\section{Loss of interleukin-10 activates innate immunity to eradicate adult T-cell leukemia-initiating cells}

Hiba El Hajj, ${ }^{1}$ Rita Hleihel,,${ }^{2,3}$ Marwan El Sabban, ${ }^{3}$ Julie Bruneau,, 4 Ghazi Zaatari, ${ }^{6}$ Morgane Cheminant, ${ }^{4,7}$ Ambroise Marcais, ${ }^{7,8}$ Abdou Akkouche,${ }^{1}$ Hideki Hasegawa, ${ }^{9}$ William Hall, ${ }^{10,11}$ Hugues De Thé, ${ }^{12-14}$ Olivier Hermine ${ }^{4,7}$ and Ali Bazarbachi ${ }^{2,3}$

${ }^{1}$ Department of Experimental Pathology, Immunology and Microbiology, Faculty of Medicine, American University of Beirut, Beirut, Lebanon; ${ }^{2}$ Department of Internal Medicine, Faculty of Medicine, American University of Beirut, Beirut, Lebanon; ${ }^{3}$ Department of Anatomy, Cell Biology and Physiological Sciences, Faculty of Medicine, American University of Beirut, Beirut, Lebanon; ${ }^{4}$ Institut Imagine - INSERM U1163, Necker Hospital, University of Paris, Paris, France; ${ }^{5}$ Department of Pathology, Necker Hospital, University of Paris, Assistance Publique Hôpitaux de Paris, Paris, France; ${ }^{6}$ Department of Pathology and Laboratory Medicine, Faculty of Medicine, American University of Beirut, Beirut, Lebanon; ' ${ }^{7}$ epartment of Hematology, Necker Hospital, University of Paris, Assistance Publique Hôpitaux de Paris, Paris, France; ${ }^{8}$ INSERM UMR 1151, University of Paris, Paris, France; ${ }^{2}$ National Institute of Infectious Diseases, Tokyo, Japan; ${ }^{10}$ University College Dublin, Dublin, Ireland; ${ }^{11} \mathrm{GI}$ CoRE, Center for Zoonosis Control, Hokkaido University, Sapporo, Japan; ${ }^{12}$ INSERM UMR 944, Equipe Labellisée par la Ligue Nationale contre le Cancer, Institut Universitaire d'Hématologie, Hôpital St. Louis, Paris, France; ${ }^{13}$ CNRS UMR 7212, Hôpital St. Louis, Paris, Paris France and ${ }^{14}$ College de France, Paris, France

\section{ABSTRACT}

A dult T-cell leukemia/lymphoma (ATL) is associated with chronic human T-cell leukemia virus type 1 infection and carries a poor prognosis. Arsenic trioxide (AS) and interferon-alpha (IFNa) together selectively trigger Tax viral oncoprotein degradation and cure Tax-driven murine ATL. AS/IFNa/zidovudine treatment achieves a high response rate in patients with chronic ATL. Interleukin 10 (IL-10) is an immuno-suppressive cytokine whose expression is activated by Tax. Here we show that, in ATL, AS/IFNa-induced abrogation of leukemiainitiating cell activity requires IL-10 expression shutoff. Loss of IL-10 secretion drives production of inflammatory cytokines by the microenvironment, followed by innate immunity-mediated clearance of Tax-driven leukemic cells. Accordingly, anti-IL-10 monoclonal antibodies significantly increased the efficiency of AS/IFN $\alpha$ therapy. These results emphasize the sequential targeting of malignant ATL cells and their immune microenvironment in leukemia-initiating cell eradication and provide a strong rationale to test the AS/IFNa/anti-IL10 combination in ATL.

\section{Introduction}

Adult T-cell leukemia/lymphoma (ATL) is a rare hematologic malignancy with a dismal prognosis ${ }^{1}$ and is initiated by the human T-cell leukemia virus type 1 (HTLV1). ${ }^{2}$ ATL develops after an extended latency period and is preceded by oligoclonal expansion of activated HTLV-1-infected T cells, ${ }^{3}$ as a result of initial expression of the viral transactivator Tax. Tax modulates several cellular pathways ${ }^{4-7}$ and is a powerful oncogene; transgenic expression of Tax alone in mice induces murine ATL. ${ }^{8}$ Although Tax protein expression is very low in most patients with ATL, long-term survival of the bulk of ATL cells may depend on transient bursts of Tax expression in some, if not the majority, of ATL cells and/or in HTLV-1-infected nonmalignant cells. ${ }^{9.11}$ This renders Tax an attractive therapeutic target, which has been further asserted by the efficacy of a Tax peptide-pulsed dendritic cell vaccine in treating patients with Tax-positive ATL. ${ }^{12}$

\section{Ferrata Storti Foundation}

\section{Correspondence: ALI BAZARBACHI \\ bazarbac@aub.edu.lb \\ OLIVIER HERMINE ohermine@gmail.com \\ HIBA EL HAJJ \\ he21@aub.edu.lb}

Received: June 24, 2020.

Accepted: December 4, 2020.

Pre-published: February 11, 2021.

https://doi.org/10.3324/haematol.2020.264523

(C)2021 Ferrata Storti Foundation

Material published in Haematologica is covered by copyright. All rights are reserved to the Ferrata Storti Foundation. Use of published material is allowed under the following terms and conditions:

https://creativecommons.org/licenses/by-nc/4.0/legalcode. Copies of published material are allowed for personal or internal use. Sharing published material for non-commercial purposes is subject to the following conditions:

https://creativecommons.org/licenses/by-nc/4.0/legalcode, sect. 3. Reproducing and sharing published material for commercial purposes is not allowed without permission in writing from the publisher. 
Zidovudine (AZT) and interferon-alpha (IFNa) have demonstrated clinical efficacy in patients with leukemic subtypes of ATL.13-17 However, the disease in several patients is primary or secondary resistant to the therapy and progresses or relapses even after a long period of disease control. This highlights the need for more effective therapies to increase the response rate, improve long-term disease control and, most importantly, eradicate the disease. One approach to improve therapy is targeting ATL leukemia-initiating cells (LIC). Arsenic trioxide (AS) and IFN $\alpha$, in combination, degrade Tax and selectively induce cell cycle arrest and apoptosis in ATL cells. ${ }^{18,19}$ Patients with ATL treated with a combination of AS, IFNa and AZT achieved complete remission ${ }^{20}$ and some of them had a long-lasting responses, even after treatment withdrawal, ${ }^{21}$ suggesting an effect of the treatment on ATL LIC. Similarly, a recent study showed unprecedented prolonged remissions of ATL in patients who received AS/IFN $\alpha / A Z T$ as a consolidation therapy, with molecular studies demonstrating disappearance of a predominant malignant clone in one patient. ${ }^{22}$ Although relapse occurred later, it was due to a different clone. ${ }^{22}$ Likewise, in Tax-driven murine ATL, AS and IFN $\alpha$ cooperate to cure leukemia through an immediate loss of LIC, and a delayed exhaustion of tumor cells, proving the feasibility of selective targeting of ATL LIC. ${ }^{21}$ Of note, LIC activity was measured and defined as the ability of these cells to initiate leukemia in serial transplantation assays.

At diagnosis, the immunosuppressive profile of patients with ATL is mostly characterized by high levels of interleukin-10 (IL-10), ${ }^{23,24}$ which stimulates the proliferation of HTLV-1-infected cells through activation of STAT3 signaling. ${ }^{25}$ In patients with ATL responding to AS/IFNa/AZT treatment, we documented a sharp decrease of IL-10 and a significant increase of IL-2 and IFN-gamma (IFN $\gamma$ ), hence restoring an immunocompetent profile. ${ }^{24}$

In the present report, we demonstrate a critical role for innate immunity, particularly macrophages and natural killer (NK) cells in AS/IFNa-induced abrogation of ATL LIC activity. Mechanistically, this combination induces loss of IL-10 production by Tax-driven leukemic cells, triggering a subsequent production of pro-inflammatory cytokines by the microenvironment, and activation of innate immunity that eventually mediates clearance of ATL LIC activity. Treatment with the triple combination of AS, IFNa and anti-IL-10 monoclonal antibodies yielded high cure rates in a mouse ATL model. This provides the rationale for clinical trials combining AS/IFNa/AZT with IL-10 suppressive therapy to treat ATL. Beyond ATL, our data reinforce the concept of dual targeting of malignant cells and their immune microenvironment to eradicate LIC activity.

\section{Methods}

\section{Treatments}

AS was obtained from Sigma-Aldrich (St Louis, USA) and recombinant human IFNa (Roferon ${ }^{\circledR}$ ) from Hoffman-La Roche (Basel, Switzerland). The proteasome inhibitor PS341 or bortezomib (Velcade $\left.{ }^{\oplus}\right)$ was purchased from Millenium Pharmaceuticals. For in vivo experiments, mice received AS (5 $\mu \mathrm{g} / \mathrm{g} /$ day) intraperitoneally, IFNa (10 $\mathrm{IU} /$ day) subcutaneously, and bortezomib $(0.5 \mathrm{mg} / \mathrm{Kg} / \mathrm{day})$ through mini-osmotic pumps (Alzet, Charles River). Treatment protocols were initiated at day 15 (bortezomib) or day 18 (AS and IFNa) following intraperitoneal injection of spleen cells from tax transgenic mice (spleen cells), and given for the duration of 6 days (bortezomib) or 3 days (AS and IFN $\alpha$ ).

Anti-IL-10 antibody (JES5-2A5, BioXCell, EUROMEDEX) or its isotype control (InVivoMAb rat IgG1, BioXCell), were administered by intraperitoneal injection, starting on day 7 after injection of spleen cells. These antibodies were given at the dose of $500 \mu \mathrm{g}$ on a biweekly basis for 2 weeks, followed by a continuous biweekly dose of $200 \mu \mathrm{g}$ in surviving mice until the animals' death or sacrifice.

Recombinant mouse IL-10 (Biolegend, Ozyme) was given once weekly by intraperitoneal injection at the dose of $200 \mathrm{ng}$ to secondary ATL mice starting on day 7 following injection of spleen cells from AS/IFN $\alpha$-treated primary mice.

Clodronate or empty liposomes were obtained from Encapsula NanoSciences LLC and administered intraperitoneally at the dose of $50 \mathrm{mg} / \mathrm{kg}$, starting on day 3 following intraperitoneal injection of spleen cells twice weekly over 2 consecutive weeks, followed by one injection in the third week.

Anti-NK1.1 antibody (clone PK136) or its mouse IgG isotype control was obtained from BioXCell. Starting on day 3 after injection of spleen cells in SCID mice, both antibodies were administered intraperitoneally, at the dose of $250 \mu \mathrm{g}$, on a weekly basis, until the death of the mice.

\section{Mice}

A murine ATL transplantation model in which $10^{6}$ unsorted spleen cells from two independent tax transgenic mice that developed murine ATL ${ }^{8,21}$ was used throughout the study. Spleen cells were inoculated intraperitoneally into SCID mice (Charles River, France). All recipient mice rapidly developed massive hyperleukocytosis, splenomegaly, hypercalcemia, multiple organ invasion, and constitutive activation of nuclear factor- $\mathrm{\kappa} B$. Tax expression was detectable only at very low levels by quantitative polymerase chain reaction (PCR) (Online Supplementary Figure S1A). These features are reminiscent of those in patients with ATL or tax transgenic mice. All untreated mice died within 3 to 4 weeks and these murine ATL could be serially passaged for years, with very constant time-to-death in all recipients, pointing to the remarkable stability of this murine ATL model.

To study the role of the innate immune microenvironment in recipient mice, primary ATL SCID mice were treated with AS/IFNa for 3 days. Spleen-derived cells were transplanted into secondary SCID or NOG SCID mice (Jackson, USA) that were left untreated and sacrificed weekly. In serial transplantation assays, spleen-derived cells from weekly sacrificed secondary ATL SCID mice were injected into tertiary SCID or NOG SCID mice and subsequently quaternary SCID mice.

All mice protocols were approved by the Institutional Animal Care and Utilization Committee of the American University of Beirut. All animals were housed in specific pathogen-free housing. Animals were sacrificed by cervical dislocation following deep anesthesia with isoflurane.

\section{Patients'cells}

Peripheral blood mononuclear cells (PBMC) from two normal donors, three patients with chronic ATL and three patients with acute ATL were separated using Ficoll and cultured in RPMI supplemented with $10 \%$ fetal bovine serum and antibiotics. Blood was collected after informed consent in accordance with the Declaration of Helsinki. PBMC were treated, ex-vivo, with arsenic $(1 \mu \mathrm{M})$ and IFNa $\left(10^{3} \mathrm{IU}\right)$ for $24 \mathrm{~h}$, and sorted based on CD25 expression. Transcript levels of IL-10 were quantified by real-time $\mathrm{PCR}$ in both $\mathrm{CD} 25^{+}$and $\mathrm{CD} 25^{-}$subpopulations using appropriate primers (Table 1). 
A
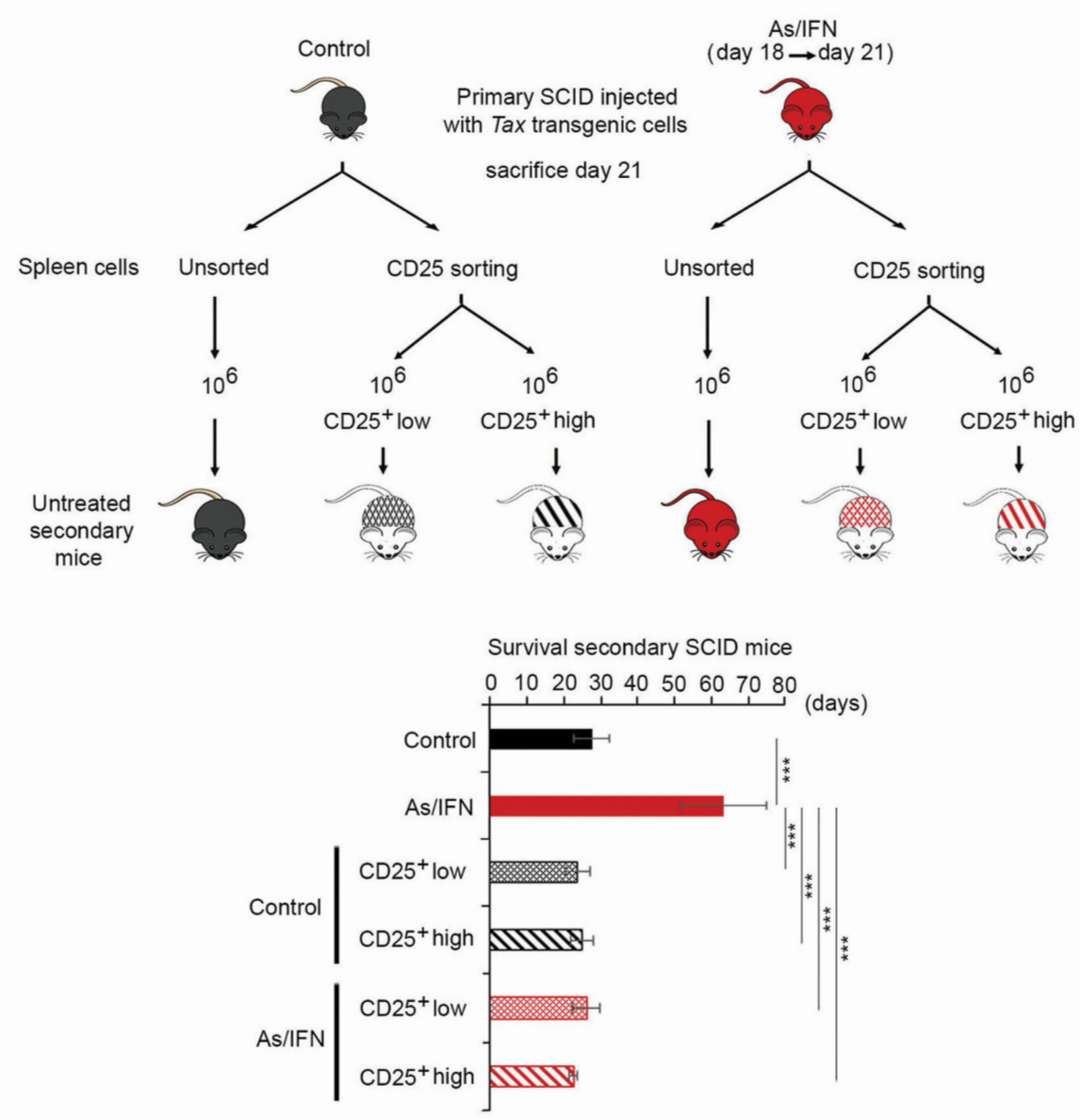

B

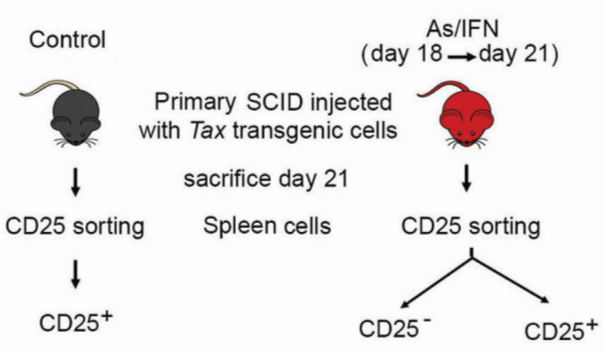

Survival secondary SCID mice

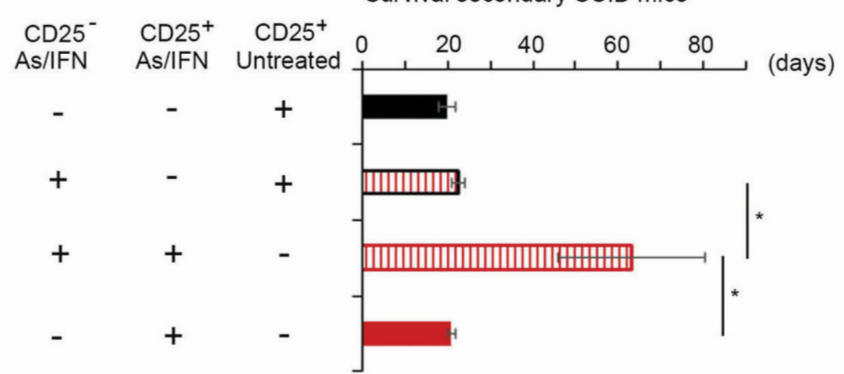

C

As/IFN

(day $18 \rightarrow$ day 21 )

Primary SCID injected with Tax transgenic cells

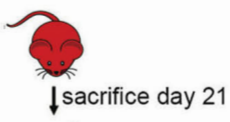

Unsorted spleen cells

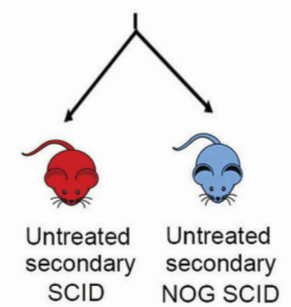

Survival secondary mice

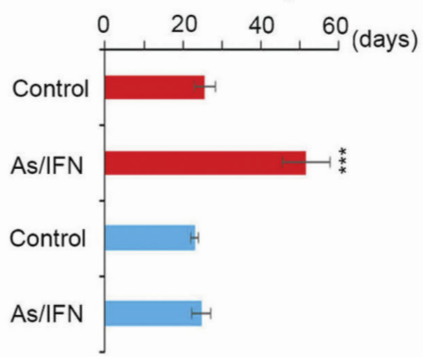


Figure 1. Arsenic and interferon- $\alpha$ target adult T-cell leukemia/lymphoma cells and their innate immunity to abrogate adult T-cell leukemic-initiating cell activity. (A) SCID mice were injected with $10^{6}$ cells, derived from the tumoral spleen of tax transgenic mice that developed adult T-cell leukemia/lymphoma (ATL), treated with arsenic trioxide (AS) and interferon-alpha (IFN ) from day 18, for 3 days, then sacrificed. One million unsorted or sorted CD25 $5^{\text {thigh }}$ or CD25 $5^{\text {tlow }}$ spleen-derived cells from primary recipients were injected into secondary SCID mice. Survival of untreated secondary recipients injected with unsorted spleen cells from untreated (control) and AS/IFN $\alpha$-treated primary mice are shown in black and red, respectively ( $n=10$ per condition). Survival of untreated secondary recipients injected with $\mathrm{CD} 25^{\text {thigh }}$ or $\mathrm{CD} 25^{\text {tlow }}$ cells from untreated primary mice (control) are shown in black crossed and dashed histograms, respectively; those from AS/IFN $\alpha$-treated primary mice are shown in red crossed and dashed histograms, respectively ( $n=4 /$ condition). (B) One million CD25 ${ }^{+}$cells from control or AS/IFN $\alpha$-treated primary mice were injected alone ( $n=5$ per condition) or together with $10^{6}$ spleen-derived CD25 cells from AS/IFN $\alpha$-treated primary mice into secondary SCID mice ( $n=3 /$ condition). Survival of untreated secondary SCID mice injected with $\mathrm{CD}_{2} 5^{+}$cells from control or AS/IFN $\alpha$-treated primary mice are represented in black and red histograms, respectively. Survival of secondary SCID mice injected with $\mathrm{CD} 25^{+}$cells from control mice and CD $25^{-}$cells from AS/IFN $\alpha$-treated primary mice are represented by a dashed red histogram (black contour line). Survival of secondary SCID mice injected with CD $25^{+}$cells and CD25 cells from AS/IFN $\alpha$-treated primary mice are represented by a dashed red histogram (red contour line). (C) Survival of untreated secondary SCID (red histograms) and NOG SCID (blue histograms) mice injected with $10^{6}$ unsorted spleen cells from control or AS/IFN $\alpha$-treated primary SCID mice ( $\mathrm{n}=7 /$ condition). The $t$-test was performed to validate significance. * $P \leq 0.05, * * P \leq 0.01$, and $* * * P \leq 0.001$. $P$-values $\leq 0.05$ were considered statistically significant.

\section{Other materials and statistical analysis}

Cell lines, their treatment and their transduction with short hairpin RNA (shRNA), flow cytometry and cell sorting, apoptosis assays, quantitative PCR, immunoblot analysis, enzyme-linked immunosorbent assays (ELISA), $\beta$-glactosidase histochemical staining and the statistical analysis are described in the Online Supplementary Methods section.

\section{Results}

\section{Arsenic and interferon- $\alpha$ target both Tax-driven leukemic cells and their microenvironment to abrogate adult T-cell leukemic-initiating cell activity}

SCID mice were injected with tax transgenic malignant cells and subsequently left untreated or were treated with AS and IFN $\alpha$ for 3 days starting on day 18, then sacrificed. As previously reported, ${ }^{21}$ this short-term treatment of primary mice did not affect tumor load (reflected by Tax transgene DNA) or Tax expression in the leukemic cells (Online Supplementary Figure S1A). One million unsorted spleen-derived cells were then injected into untreated secondary recipient SCID mice. As previously reported, ${ }^{21}$ the survival of secondary recipients transplanted with cells from previously treated mice was longer than that of secondary recipients transplanted with cells from untreated mice (Figure $1 \mathrm{~A}$ ), reproducing the formerly reported loss of ATL LIC activity in mice treated with AS/IFNa. ${ }^{21}$ To investigate the basis of this effect, we sorted spleenderived cells from untreated or AS/IFN $\alpha$-treated primary transplanted mice based on CD25 (CD25-, CD25 $5^{\text {tow }}$ or CD25 $\left.5^{\text {high }}\right)$. CD25 is expressed on normal regulatory $\mathrm{T}$ cells but is also highly expressed in ATL cells. ${ }^{8}$ Both CD25 $5^{\text {thigh }}$ and $\mathrm{CD} 25^{\text {tlow }}$ fractions contained bona fide leukemic cells as they carried the tax transgene, unlike the CD25- cells (Online Supplementary Figure S1B). Both $\mathrm{CD} 25^{\text {thigh }}$ and CD25 $5^{\text {tow }}$ fractions displayed similar LIC activities, as all secondary recipients inoculated with $10^{6}$ cells from either subpopulations developed leukemia (Online Supplementary Figure $S 1 C-E$ ) and succumbed at 3 weeks after injection (Figure 1A). Conversely, leukemia development was not observed in secondary recipients of CD25- cells (data not shown).

Treatment with AS/IFN $\alpha$ induced a slight decrease of the percentage of $\mathrm{CD}_{2} 5^{+}$cells, predominantly the CD25 thigh fraction (Online Supplementary Figure S1F). Importantly, fractions of $\mathrm{CD} 25^{+}$cells derived from AS/IFNa-treated primary recipients exhibiting features of apoptosis or senescence were similar to those of CD25+ cells from untreated primary recipients (Online Supplementary Figure $S 1 G-I)$. Moreover, as previously reported ${ }^{21}$ and in agreement with the loss of LIC activity, ${ }^{21}$ treatment of primary mice with AS/IFN $\alpha$ reduced the tumor bulk (defined as spleen weight $\mathrm{x}$ tax DNA) in untreated secondary recipient SCID mice (Online Supplementary Figure S1J). Importantly, sorted CD25+ cells derived from AS/IFN $\alpha$-treated primary mice exhibited preserved LIC activity, contrary to unsorted spleen cells (Figure 1A). This prompted us to investigate whether the effect of AS/IFN $\alpha$ on LIC activity was mediated by the Tax-negative non-ATL CD25- population. SCID mice were thus injected with $10^{6}$ CD25 cells from AS/IFNatreated primary mice along with $10^{6} \mathrm{CD}^{2} 5^{+}$cells from either untreated or AS/IFN $\alpha$-treated primary mice (Figure 1B). The survival of untreated secondary recipient mice was significantly increased only when they were injected with both $\mathrm{CD}_{25} 5^{-}$and $\mathrm{CD} 25^{+}$cells derived from AS/IFN $\alpha$ treated primary mice (Figure $1 \mathrm{~B}$ ). This result suggests that AS and IFNa exert a dual effect on both Tax-driven leukemic cells and non-leukemic cells to abrogate ATL LIC activity.

To directly assess whether AS/IFN $\alpha$-induced loss of ATL LIC activity involves the innate immunity, we took advantage of the difference in the immune background of SCID and NOG SCID mice. While SCID mice are known to have natural killer (NK) cells and functional macrophages, NOG SCID mice lack NK cells and have impaired macrophage functions. ${ }^{26}$ Transplantation of spleen cells derived from AS/IFN $\alpha$-treated primary SCID mice into secondary recipient SCID or NOG SCID mice revealed that the LIC activity was only abrogated in SCID mice (Figure 1C, compare red and blue histograms). All together, these results implicate the innate immune cells of both the donor and the recipient in clearance of LIC activity.

\section{A critical role for natural killer cells and macrophages in arsenic/interferon- $\alpha$-mediated suppression of adult T-cell leukemic-initiating cell activity}

The importance of the innate immunity in both donors and recipients in AS/IFN $\alpha$-induced suppression of LIC activity prompted us to further investigate the role of macrophages and NK cells in the observed phenotype. SCID mice were injected with $10^{6}$ CD $25^{+}$cells from untreated or AS/IFN $\alpha$-treated primary mice along with 25,000 sorted macrophages $\left(\mathrm{CD} 25^{-} \mathrm{CD} 11 \mathrm{~b}^{+} \mathrm{F} 4 / 80^{+}\right)$or $\mathrm{NK}$ cells $\left(\mathrm{CD} 25^{-} \mathrm{CD} 335^{+}\right)$from AS/IFN $\alpha$-treated primary mice (Figure 2A). Significantly increased survival was observed exclusively in untreated secondary recipients injected with $\mathrm{CD}_{25} 5^{+}$cells from AS/IFNa-treated primary mice together with either macrophages or NK cells also derived from AS/IFN $\alpha$-treated primary mice (Figure 2A, Online Supplementary Figure S2A). These results demonstrate a 
A

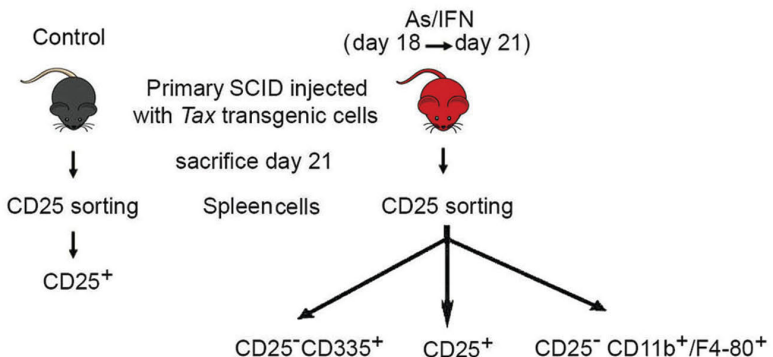
$\mathrm{CD}^{-} 5^{-} \mathrm{CD}_{11 \mathrm{~b}^{+} / \mathrm{F} 4-80^{+}}$
As/lFN

$\begin{array}{ccc}\mathrm{CD}^{-} 5^{-} \mathrm{CD} 335^{+} & \mathrm{CD}^{+} 5^{+} & \mathrm{CD}^{+} 5^{+} \\ \text {As/lFN } & \text { As/lFN } & \text { Untreated }\end{array}$

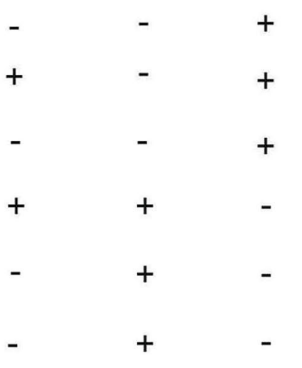

B

$10^{6}$ unsorted spleen cells from untreated mice or $10^{6}$ unsorted spleen cells from As/IFN treated mice

I Empty lipososmes or chlodronate
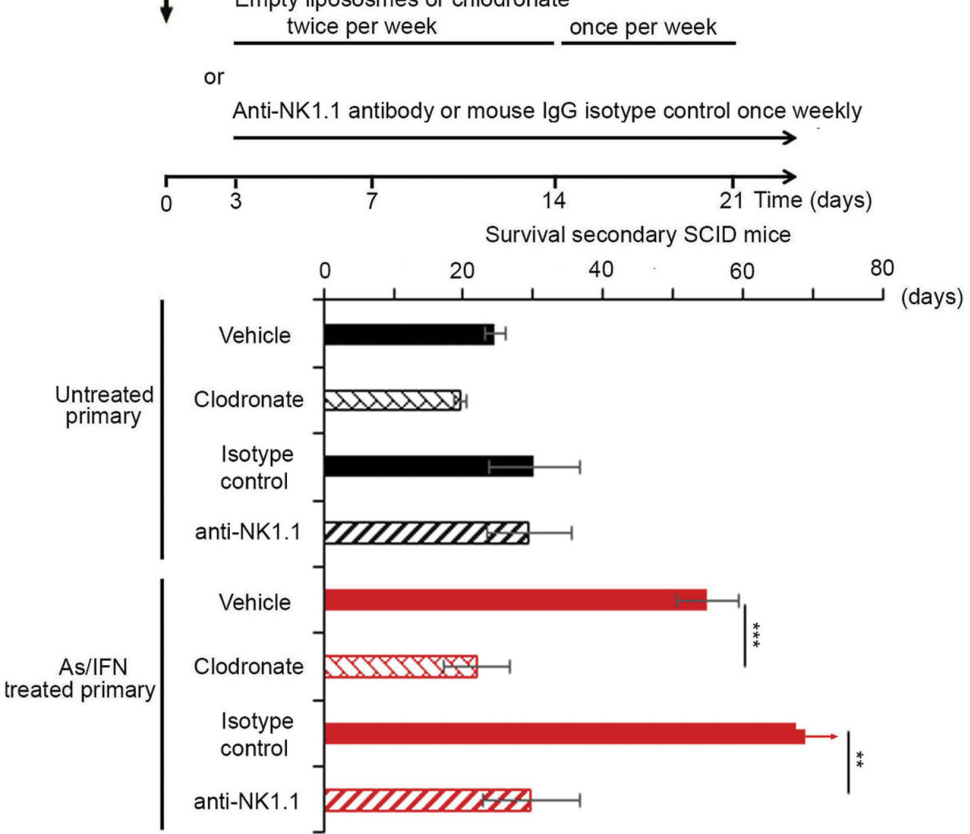

C
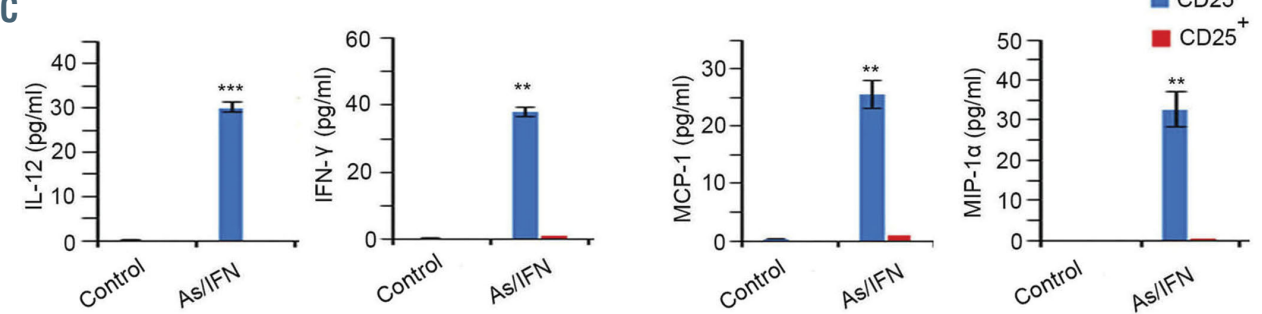

Figure 2. A critical role for natural killer cells and macro-phages in arsenic/interferon-mediated suppression of adult T-cell leukemic-initiating cell activity. (A) The same experimenta design as shown in Figure $1 \mathrm{~A}$ was followed. Histograms represent survival of untreated secondary SCID mice injected with $10^{6} \mathrm{CD}^{2} 5^{+}$cells from untreated (control; $n=5$ black histograms) or arsenic trioxide (AS)/interferon alpha (IFN $\alpha$ )-treated primary mice ( $n=5$ red histograms); survival of untreated secondary SCID mice injected with $10^{6}$ $\mathrm{CD}^{+} 5^{+}$cells from untreated primary mice and $25,000 \mathrm{CD} 25$ $\mathrm{CD}_{3} 35^{+} \mathrm{NK}$ cells from AS/IFN $\alpha$ treated primary mice $(n=3$ vertically dashed red histogram with black contour line); survival of untreated secondary SCID mice injected with $10^{6} \mathrm{CD} 25$ cells from AS/IFN $\alpha$-treated primary mice and 25,000 CD25 $\mathrm{CD}_{3} 35^{+}$cells from AS/IFN $\alpha$ treated primary mice $(n=3$ vertically dashed red histogram with red contour line); survival of untreated secondary SCID mice injected with $10^{6} \mathrm{CD} 25^{+}$cells from untreated primary mice and 25,000 $\mathrm{CD}^{2} 5^{-} \mathrm{CD} 11 \mathrm{~b}$ $\mathrm{F} 4 / 80^{+}$cells (macrophages) from AS/IFN $\alpha$-treated primary mice $(n=4$ oblique dashed red histogram with black contour line); and survival of untreated secondary SCID mice injected with $10^{6} \mathrm{CD}^{2} 5^{+}$cells from AS/IFN $\alpha$-treated primary mice and 25,000 $\mathrm{CD}^{2} 5^{-} \mathrm{CD} 11 \mathrm{~b}^{+} \mathrm{F} 4 /$ $80^{+}$cells from AS/IFN $\alpha$-treated primary mice $(n=4$ oblique dashed red histogram with red contour line). (B) Secondary SCID mice were injected with $10^{\circ}$ unsorted spleen cells from untreated (black histograms) or AS/IFN $\alpha$-treated (red histograms) primary SCID mice wth adult T-cell leukemia/lymphoma (ATL). The secondary mice were treated with clodronate or their corresponding empty liposomes, or anti-NK1.1 antibody or mouse IgG isotype control starting on day 3 after injection of cells ( $n=5 /$ condition). (C) Enzymelinked immunosorbent assay on supernatant of homogenized $\mathrm{CD} 25^{+}$or $\mathrm{CD}^{2} 5^{-}$sorted cells derived from the spleen of untreated (control) or AS/IFN $\alpha$-treated primary mice for pro-inflammatory cytokines (IL-12 and IFN $\gamma$ ), as well as the pro-inflammatory monocyte chemoattractant protein-1 (MCP$1 / C C L 2)$ and the macrophage inflammatory protein 1-alpha (MIP-1 $\alpha$ ) chemokines. The $t$-test was performed to validate significance. $* P \leq 0.05, * * P \leq 0.01$, and $* * * P \leq 0.001$. $P$-values $\leq 0.05$ were considered statistically significant. 
A

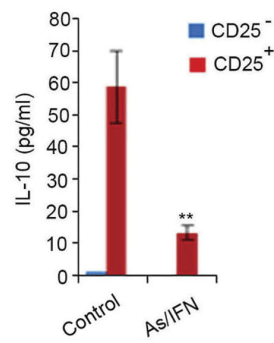

D
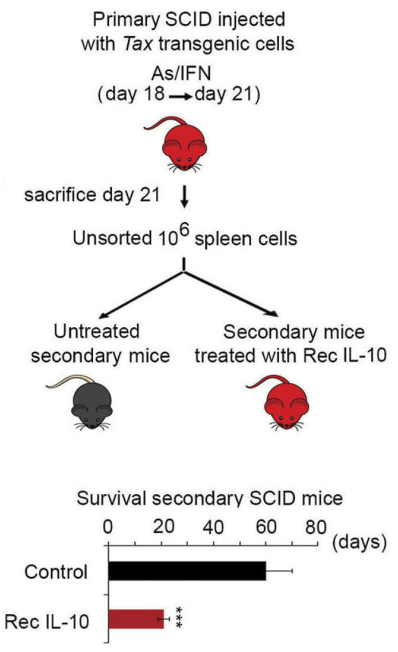

F

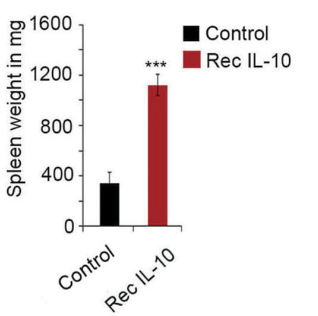

C

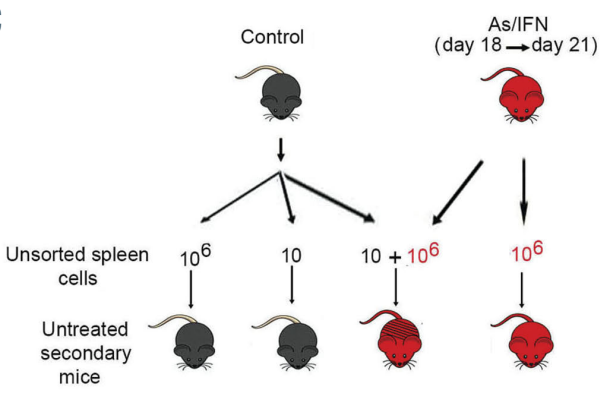

Survival secondary SCID mice

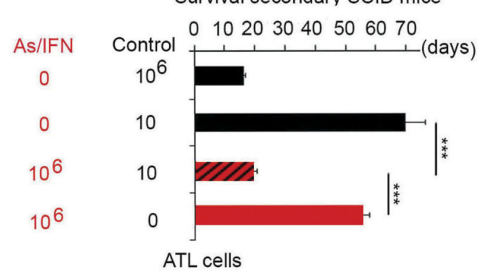

E

Primary SCID injected

with Tax transgenic cells

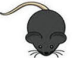

$\downarrow$ sacrifice day 21

Unsorted $10^{6}$ spleen cells<smiles>[Ga][Se]C[Se][Se]</smiles>

treated with isotype control treated with Anti-IL10

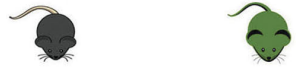

Survival SCID mice

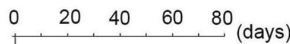

Isotype

Anti-IL10

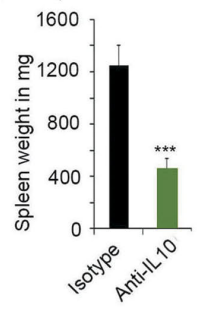

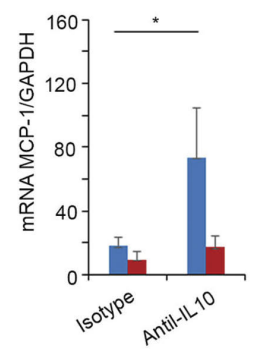
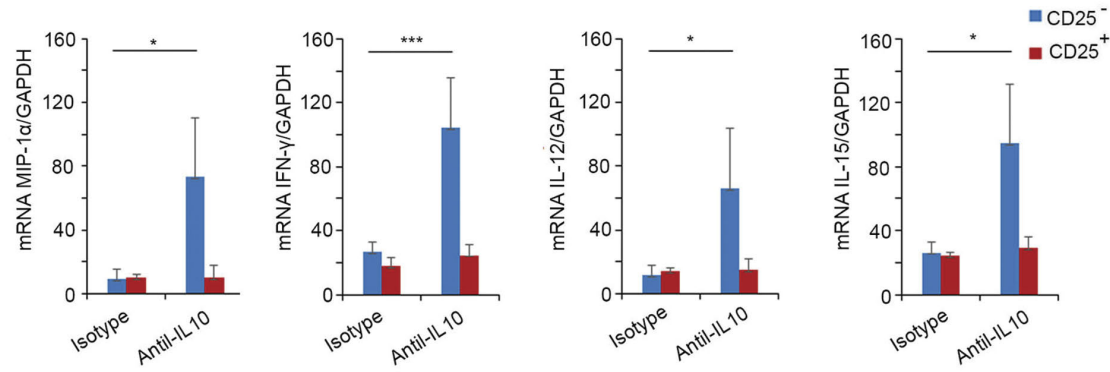

Figure 3. A critical role for the loss of interleukin-10 production in arsenic/interferon-mediated eradication of adult T-cell leukemic-initiating cell activity. (A) Enzyme-linked immunosorbent assay (ELISA) on supernatant of homogenized CD25 $5^{+}$or $\mathrm{CD}_{2} 5^{-}$sorted cells derived from the spleen of untreated (control) or arsenic trioxide (AS)/interferon alpha (IFN $\alpha$ )-treated primary mice. (B) ELISA on plasma of normal SCID mice ( $n=3$; gray histogram) or SCID mice with adult T-cell leukemia/lymphoma (ATL) injected with $10^{6}$ spleen cells derived from tax transgenic mice, and left untreated ( $n=5$; black histogram) or treated with AS and IFNo from day 18 until day 21 ( $n=5$; red histogram). (C) Survival of untreated secondary SCID mice injected with $10^{6}$ or ten unsorted spleen cells from untreated (control) primary ATL mice ( $n=3$ and $n=4$, respectively; black), $10^{6}$ cells from primary mice treated with AS/IFN $\alpha$ for 3 days $(n=8$; red), or ten cells from untreated primary mice together with $10^{6}$ cells from primary mice treated with AS/IFN $\alpha$ for 3 days ( $n=8$; red-black dashed). (D) Survival and spleen weight of secondary recipient SCID mice injected with $10^{6}$ unsorted spleen cells derived from primary mice treated with AS/IFN $\alpha$. These secondary recipients were left untreated (control; black histograms) or treated with recombinant murine (Rec-m) interleukin 10 (IL-10) (red; $n=7 /$ condition). (E) Spleen weight and survival of primary ATL SCID mice ( $n=7 /$ condition) treated with anti-IL-10 antibodies (green histogram) or control isotype (black histogram). (F) Quantitative reverse transcriptase polymerase chain reaction analysis of homogenized $\mathrm{CD} 25^{+}$or $\mathrm{CD} 25$ sorted cells derived from the spleens of untreated primary mice or primary mice treated with anti-IL-10 antibodies. The $t$-test was performed to validate significance. ${ }^{*} P \leq 0.05, * * P \leq 0.01$, and $* * * P \leq 0.001$. $P$-values $\leq 0.05$ were considered statistically significant. 
critical role for macrophages and NK cells of the primary donor mice in AS/IFNa-induced abrogation of ATL LIC activity.

These results prompted us to deplete macrophages or NK cells in the recipient mice using clodronate or antiNK1.1 antibody, respectively. For macrophage depletion in the recipient mice, we used clodronate treatment. ${ }^{27}$ Secondary recipient SCID mice, injected with $10^{6}$ unsorted spleen cells from either untreated or AS/IFN $\alpha$-treated primary mice, were treated with empty liposomes or clo- dronate (see experimental design in Figure 2B). Macrophage depletion was confirmed by flow cytometry based on the reduction of $\mathrm{CD} 25^{-} \mathrm{CD} 11 \mathrm{~b}^{+} \mathrm{F} 4 / 80^{+}$cells (Online Supplementary Figure S2B). Clodronate treatment abrogated the effects of AS/IFN $\alpha$ and restored ATL LIC activity (Figure 2B, Online Supplementary Figure S2B), confirming the critical role of macrophages of secondary recipients in the AS/IFN $\alpha$-induced cure.

For NK-cell depletion in the recipient mice, secondary recipient SCID mice, injected with $10^{6}$ unsorted spleen

A

$$
\begin{gathered}
\text { As/IFN } \\
\text { (day } 18 \rightarrow \text { day 21) }
\end{gathered}
$$

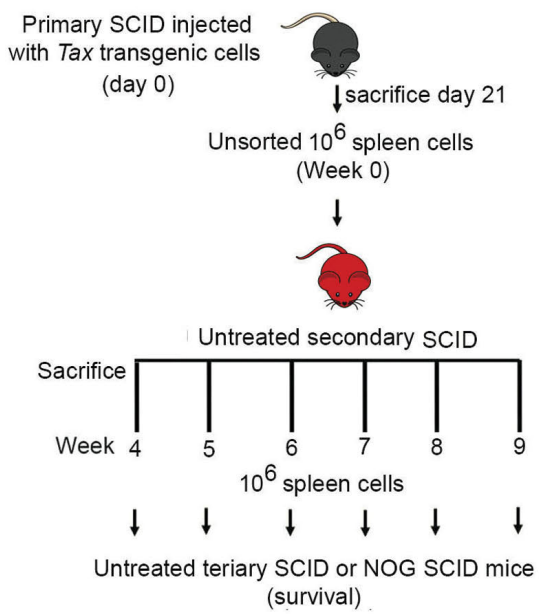

D

$$
\begin{gathered}
\text { As/IFN } \\
\text { (day } 18 \rightarrow \text { day }
\end{gathered}
$$

(day $18 \rightarrow$ day 21)

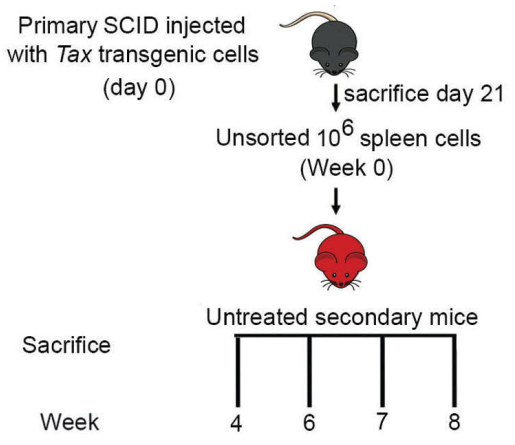

B

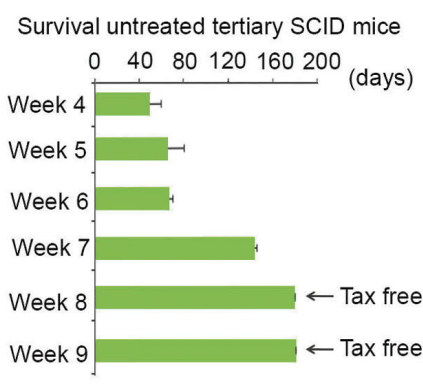

C

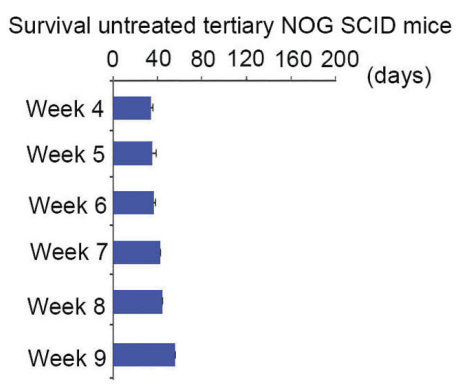

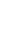
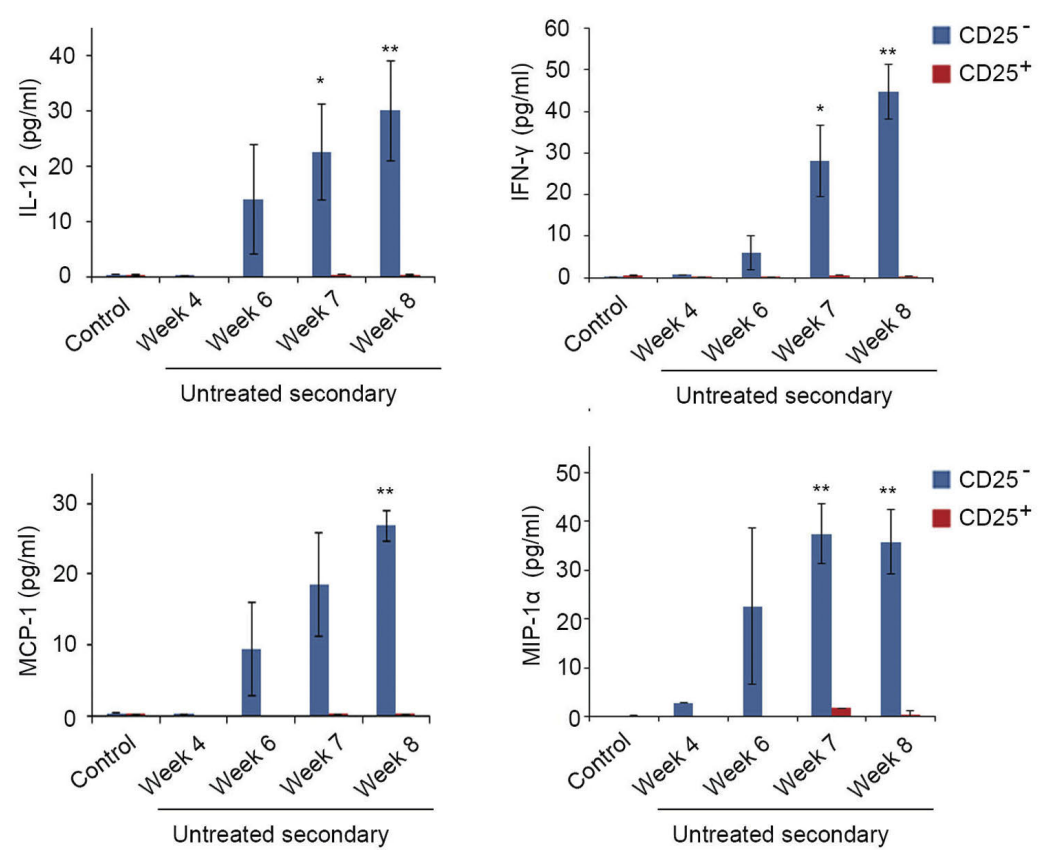

Figure 4. Loss of leukemia-initiating cell activity requires innate immunity. (A) Primary mice injected with cells, derived from the tumoral spleen of tax transgenic mice that developed adult T-cell leukemia/lymphoma (ATL), were treated with arsenic trioxide (AS) and interferon alpha (IFN $\alpha$ ) for 3 days then sacrificed. One million unsorted spleen-derived cells were injected into 50 secondary SCID mice that were left untreated and sacrificed on a weekly basis (5 per week). (B, C) One million unsorted spleen cells derived from weekly sacrificed untreated secondary SCID mice were injected into tertiary SCID (green histograms) (B) or NOG SCID (dark blue histograms) ( $n=10 /$ condition) (C) mice that were left untreated. (D) Enzyme-linked immunosorbent assay on supernatant of homogenized spleen-derived CD25 ${ }^{+}$and $\mathrm{CD} 25^{-}$sorted cells from weekly sacrificed untreated secondary mice injected with $10^{6}$ unsorted spleen cells from AS/IFN $\alpha$-treated primary mice. Control indicates secondary mice injected with $10^{6}$ unsorted spleen cells from untreated primary mice. The $t$-test was performed to validate significance. ${ }^{*} P \leq 0.05$, $* \star P \leq 0.01$, and $* * * P \leq 0.001$. $P$-values $\leq 0.05$ were considered statistically significant. 
A

$$
\begin{gathered}
\text { As/IFN } \\
\text { (day } 18 \rightarrow \text { day 21) }
\end{gathered}
$$
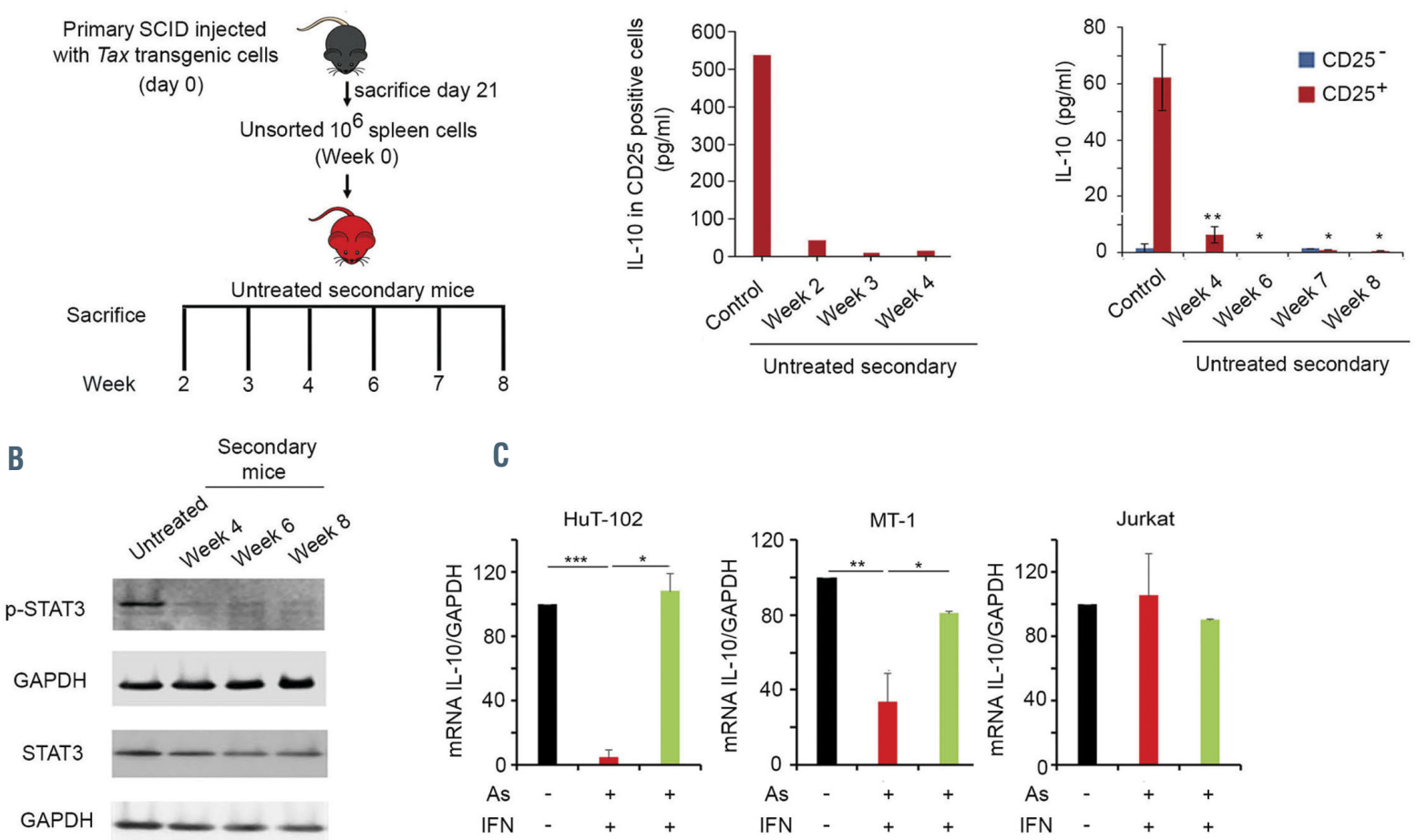

C
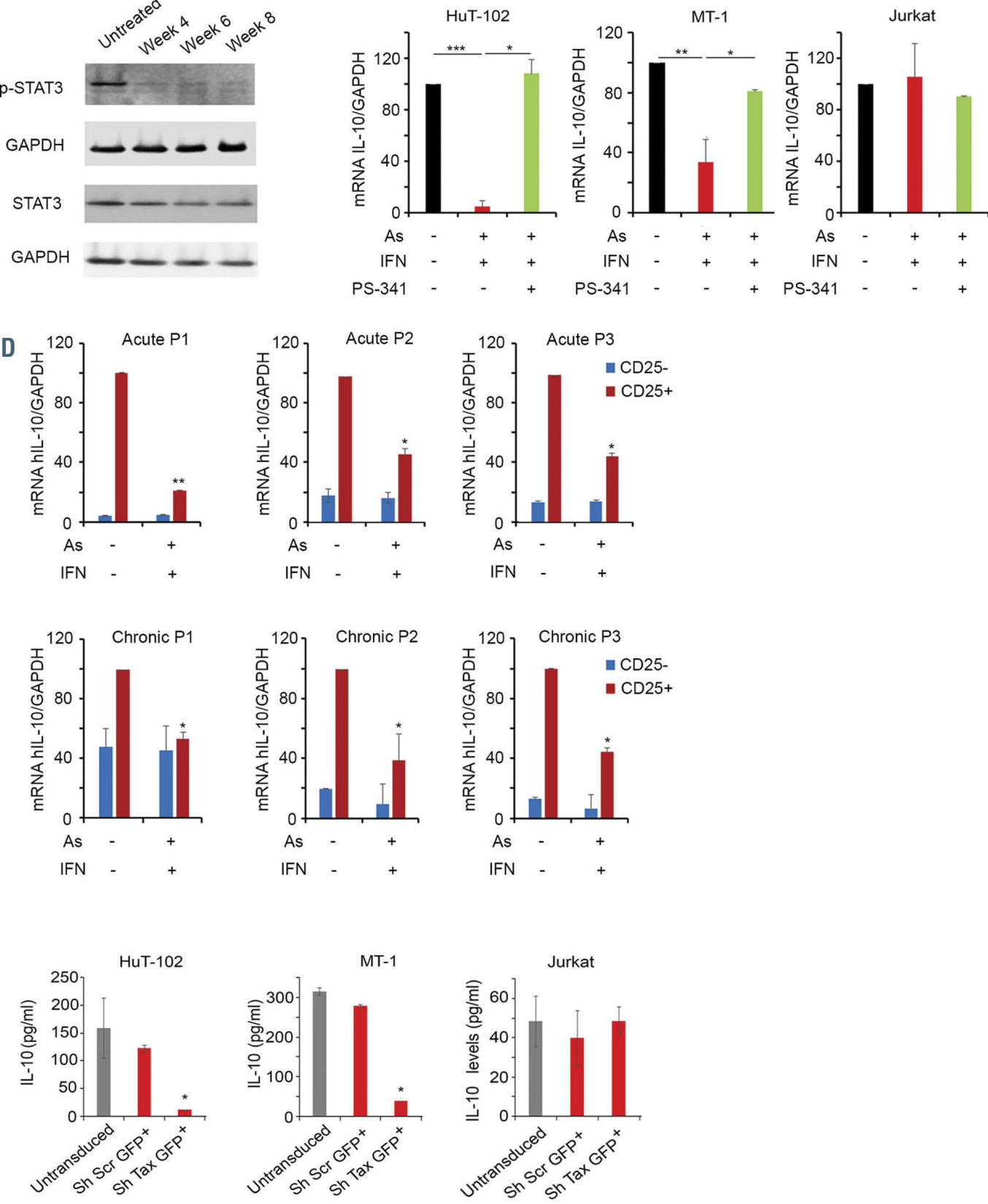

Figure 5. Legend on next page. 
Figure 5. Tax knock down in adult T-cell leukemia/lymphoma-derived cells decreased interleukin-10 production. (A) The same experimental design as that illustrated in Figure $1 \mathrm{~A}$ was followed and secondary SCID mice were left untreated and sacrificed on a weekly basis (left). Interleukin 10 (IL-10) levels were determined by enzyme-linked immunosorbent assay (ELISA) in the supernatant of $\mathrm{CD}_{2} 5^{+}$sorted spleen cells from untreated secondary mice injected with $10^{6}$ unsorted spleen cells from arsenic trioxide (AS)/interferon alpha (IFN $\alpha$ )-treated primary mice sacrificed at week 2 to 4 (each condition represents pooled cells from 3 mice, middle). IL-10 determined by ELISA in the supernatant of homogenized spleen-derived CD25 $5^{+}$and $\mathrm{CD}_{2} 5^{-}$sorted cells from untreated secondary mice injected with $10^{6}$ unsorted spleen cells from AS/IFN $\alpha$-treated primary mice sacrificed at week 4 to 8 (right). (B) Western blot for p-STAT3 and STAT3 in untreated secondary mice injected with $10^{6}$ unsorted spleen cells derived from primary mice with adult T-cell leukemia/lymphoma (ATL) treated with AS/IFNa. These secondary mice were sacrificed at weeks 4, 6 and 8. (C) Transcript levels of human IL-10 in untreated ATL-derived (HuT-102 and MT-1) or HTLV-1-negative (Jurkat) cell lines (black histograms) or after $24 \mathrm{~h}$ of ex-vivo treatment with AS/IFN $\alpha$ alone (red histograms) or combined with the proteasome inhibitor PS-341 (green histograms). (D) Transcript levels of human $\mathrm{IL}-10$ in $\mathrm{CD}^{-} 5^{-}$(blue histograms) or $\mathrm{CD}^{+} 5^{+}$(red histograms) sorted cells from freshly isolated peripheral blood mononuclear cells from six patients with ATL, after exvivo treatment with AS/IFN $\alpha$. (E) IL-10 levels (ELISA) of green fluorescent protein-positive (GFP+) sorted cells from ATL-derived (HuT-102 and MT-1) or HTLV-1-negative (Jurkat) cell lines following transduction with GFP-lentiviral vectors encoding scrambled shRNA (shScr) or shRNA against Tax (shTax). Gray and red histograms correspond to un-transduced, shScr, or shTax transduced GFP+ sorted cells as indicated. The $t$-test was performed to validate significance. $* P \leq 0.05, * * P \leq 0.01$, and $* * *$ $P \leq 0.001$. $P$-values $\leq 0.05$ were considered statistically significant.

cells from either untreated or AS/IFN $\alpha$-treated primary mice, were treated with an anti-NK1.1 antibody or with a mouse IgG isotype control (see experimental design in Figure 2B). NK-cell depletion was confirmed by flow cytometry based on the reduction of CD25-NK1.1 $1^{+}$cells (Online Supplementary Figure S2C). Importantly, NK-cell depletion abrogated the effects of AS/IFN $\alpha$ and restored ATL LIC activity (Figure 2B, Online Supplementary Figure $S 2 \mathrm{C}$ ), confirming the critical role of $\mathrm{NK}$ cells of secondary recipients in the AS/IFN $\alpha$-induced cure.

The contribution of innate immunity, namely macrophages and NK cells, to the therapeutic effects of AS/IFN $\alpha$ was further asserted by a significant increase of the production of the pro-inflammatory cytokines IL-12 and IFN $\gamma$ as well as monocyte chemoattractant protein-1 (MCP-1) and macrophage inflammatory protein 1-alpha (MIP-1 $\alpha$ ) exclusively in the CD25- spleen cell population of AS/IFN $\alpha$-treated primary mice sacrificed after 3 days of treatment (Figure 2C).

\section{Arsenic and interferon- $\alpha$ sharply decreased interleukin-10 production by Tax-driven leukemic cells, resulting in loss of leukemic-initiating cell activity and activation of innate immunity}

In addition to its effects on the production of proinflammatory cytokines by non-malignant cells, AS/IFNa treatment for 3 days significantly decreased the production of the anti-inflammatory cytokine IL-10 by CD25+ cells (Figure 3A), along with a significant decrease of IL-10 plasma levels (Figure 3B). Interestingly, baseline IL-10 plasma levels were significantly higher in ATL SCID mice than in normal SCID mice (Figure $3 \mathrm{~B}$ ). These results are quite similar to those observed in patients with ATL who display high levels of IL-10 at diagnosis, with the levels decreasing sharply after treatment with AS/IFNa/AZT. ${ }^{23,24}$ In these patients, IL-10 may be produced by ATL cells and/or by HTLV-1-infected non-malignant cells, ${ }^{23}$ or even by HTLV-1-negative cells. Indeed, HTLV-1-infected nonmalignant cells may provide an adequate environment for the growth of ATL cells. To mimic this situation, we used malignant cells derived from two different tax transgenic mice. We, therefore, transplanted into SCID mice ten or $10^{6}$ unsorted spleen cells derived from a SCID mouse injected with malignant cells from one tax transgenic animal (Figure 3C, Online Supplementary Figure S3A, black histograms), $10^{6}$ cells derived from a second SCID mouse injected with malignant cells from another tax transgenic mouse and subsequently treated with AS/IFNa (Figure 3C, Online Supplementary Figure S3A, red histograms), or a mixture of ten cells derived from the untreated SCID mouse injected with malignant cells from one tax trans-
Table 1. List of primers.

\begin{tabular}{ll}
\hline Primer & Sequence $5^{\prime} \rightarrow 3^{\prime}$ \\
mGAPDH Forward Primer & CATGGCCTTCCGTGTTCCTA \\
mGAPDH Reverse Primer & CCTGCTTCACCACCTTCTTGAT \\
\hline hGAPDH Forward Primer & GTGGACCTGACCTGCCGTCT \\
hGAPDH Reverse Primer & GGAGGAGTGGGTGTCGCTGT \\
\hline IL-10 Forward Primer & GTGATGCCCCAAGCTGAGA \\
IL-10 Reverse Primer & CACGGCCTTGCTCTTGTTTT \\
\hline hIL-10 Forward Primer & GCCTAACATGCTTCGAGATC \\
hIL-10 Reverse Primer & TGATGTCTGGGTCTTGGTTC \\
\hline IFN- $\gamma$ Forward Primer & TCAAGTGGCATAGATGTGGAAGAA \\
IFN- $\gamma$ Reverse Primer & TGGCTCTGCAGGATTTTCATG \\
\hline IL-12 Forward Primer & TCAAACCAGACCCACCGAA \\
IL-12 Reverse Primer & GCTGACCTCCACCTGCTGA \\
\hline mMCP-1 Forward Primer & CATGCTTCTGGGCCTGCTGTC \\
mMCP-1 Reverse Primer & CCTGCTGCTGGTGATCCTCTTG \\
\hline mMIP1A Forward Primer & CCTTGCTGTTCTTCTCTGTACCATG \\
mMIP1A Reverse Primer & GCATTCAGTTCCAGGTCAGTGATG \\
\hline Rantes Forward Primer & CAGCAGCAAGTGCTCCAATCTT \\
Rantes Reverse Primer & TTCTTGAACCCACTTCTTCTCTGG \\
\hline IL-15 Forward Primer & CATCCATCTCGTGCTACTTGTGTT \\
IL-15 Reverse Primer & CATCTATCCAGTTGGCCTCTGTTT \\
\hline Tax Forward Primer & CGGATACCCAGTCTACGTGT \\
Tax Reverse Primer & GAGCCGATAACGCGTCCATCG \\
\hline
\end{tabular}

genic and $10^{6}$ cells derived from the AS/IFN $\alpha$-treated SCID mouse injected with malignant cells from the other tax transgenic animcal (Figure 3C, Online Supplementary Figure $S 3 A$, red-black dashed histograms). While the shortterm treatment of primary recipients with AS/IFN $\alpha$ affected ATL LIC activity, and resulted in prolonged survival of untreated secondary recipients, adding as few as ten malignant cells from untreated animals preserved the LIC activity of Tax-driven leukemic cells from treated animals and resulted in rapid death of secondary recipients in less than 3 weeks (Figure 3C, Online Supplementary Figure S3A). These results strongly suggest that Tax-driven leukemic cells produce IL-10, and potentially other cytokines, which prevent therapy-induced loss of ATL LIC activity through a paracrine mechanism. To test this hypothesis directly, we treated secondary recipients injected with malignant cells derived from AS/IFNa-treated primary mice, with recombinant mouse IL-10 (Rec IL-10) (Figure 3D). Upon adding Rec IL-10, the weight of the spleens of all mice increased significantly and the animals succumbed to ATL in less than 3 weeks (Figure 3D). 
A

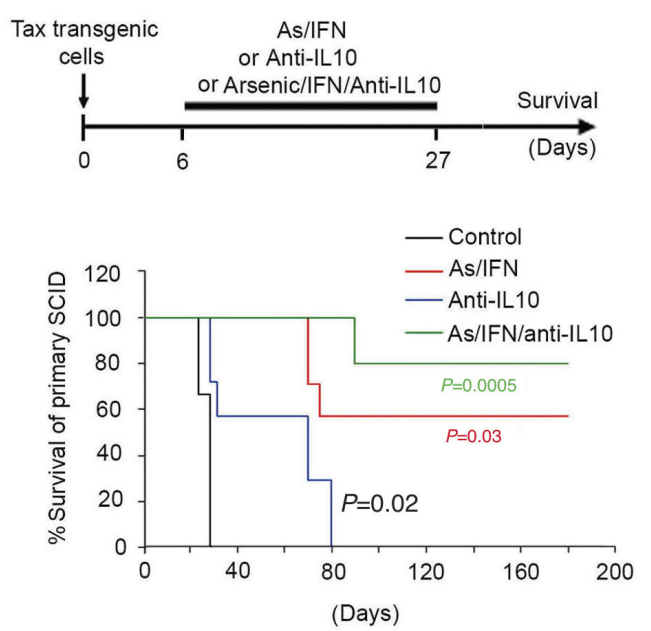

B

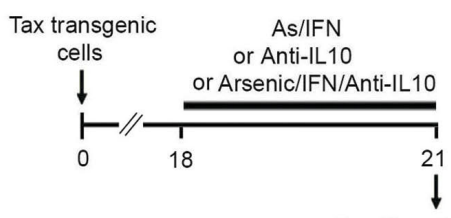

Sacrifice at week 4

Unsorted $10^{6}$ spleen ATL cells

$\downarrow$

Untreated secondary mice

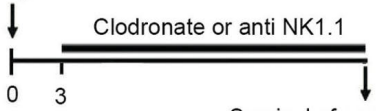

Survival of secondary mice

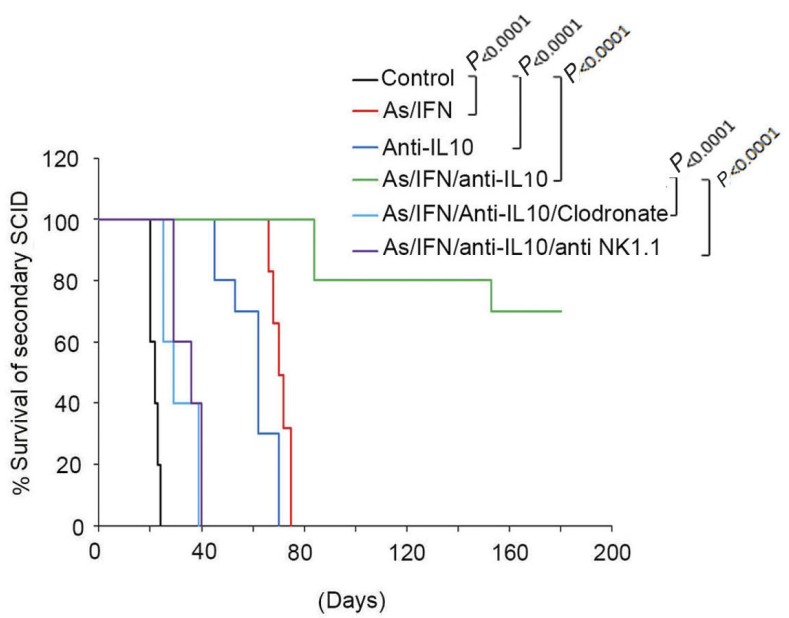

C

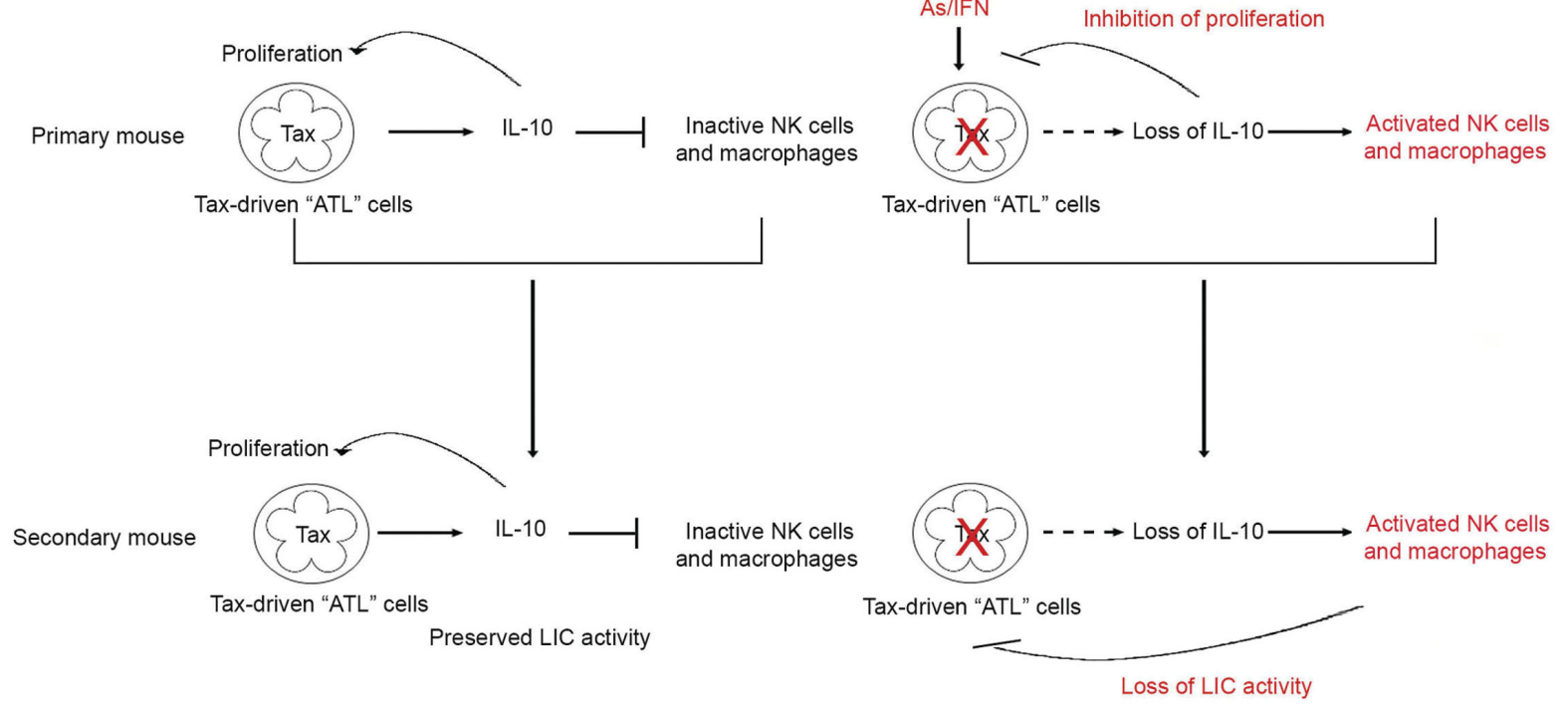

Figure 6. Combination of an anti-interleukin-10 monoclonal antibody, arsenic and interferon abrogates adult T-cell leukemic-initiating cell activity. (A) Kaplan-Meier analysis of overall survival of primary SCID mice injected with $10^{6}$ unsorted spleen cells and treated with an anti-interleukin (IL)-10 antibody (blue line; $n=5$ ), arsenic

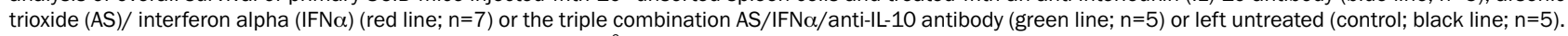
(B) Survival of secondary recipient SCID mice injected with $10^{6}$ unsorted spleen cells derived from primary SCID mice with adult T-cell leukemia/lymphoma (ATL) treated with an anti-IL-10 antibody (blue line; $n=5$ ), AS/IFN $\alpha$ (red line; $n=6$ ) or AS/IFN $\alpha /$ anti-IL-10 antibody (green line; $n=10$ ) or untreated controls (black line; $n=10$ ). Secondary SCID mice injected with $10^{6}$ spleen cells derived from primary ATL SCID treated with AS/IFN $\alpha /$ anti-IL-10 were treated with clodronate (light blue line; $n=5$ ) or anti-NK1.1 (purple line; $n=5$ ) starting on day 3 after injection of leukemic cells. (C) Proposed model for therapy-induced ATL cure: ATL cells depend on IL-10 signaling to escape from the innate immune system. Treatment with AS/IFN $\alpha$ induces Tax degradation, resulting in decreased IL-10 production, activation of NK cells and macrophages and innate immunity-mediated abrogation of ATL LIC activity. 
Conversely, treatment of secondary recipients with an anti-IL-10 monoclonal antibody significantly decreased their splenomegaly and prolonged their survival (Figure 3E, Online Supplementary Figure S3B). Importantly, untreated secondary (see Figure 6B) or tertiary (Online Supplementary Figure S3C) SCID mice serially transplanted with $10^{6}$ spleen cells derived from anti-IL-10-treated primary recipients survived significantly longer than those transplanted with spleen cells derived from untreated primary recipients. These results demonstrate a critical role for IL-10 in ATL LIC activity. Further asserting this pivotal role of IL-10, treatment of ATL SCID mice with an anti-IL10 monoclonal antibody significantly increased the production of the pro-inflammatory cytokines MCP-1, MIP$1 \alpha$, IFN $\gamma$, IL-12 and IL-15 (Figure 3F), exclusively in the $\mathrm{CD}^{-} 5^{-}$spleen cell population. These results provide direct evidence implicating the loss of IL-10 production in the observed activation of innate immunity.

Finally, AS/IFN $\alpha$-induced abrogation of IL-10 production was rescued upon co-treatment with the proteasome inhibitor PS-341 (Online Supplementary Figure S3D), in agreement with our previous finding that the curative effect of AS/IFN $\alpha$ requires intact proteasome activity, likely involving Tax degradation by the proteasome. ${ }^{21}$

\section{Arsenic and interferon- $\alpha$ induced loss of adult T-cell leukemic-initiating cell activity is associated with delayed activation of innate immunity}

Our results indicate that both AS/IFN $\alpha$-induced prevention of IL-10 production by Tax-driven leukemic cells and AS/IFN $\alpha$-induced activation of innate immunity are mandatory for the suppression of ATL LIC activity. To dissect the sequence of events, $10^{6}$ unsorted spleen-derived cells from AS/IFN $\alpha$-treated primary mice were injected into 50 SCID mice that were left untreated. Subsequently, five of these secondary recipients were sacrificed each week until week 9 (Figure 4A). The loss of ATL LIC activity was investigated by serial transplantation of spleen cells from secondary recipients into tertiary SCID or NOG SCID mice that were left untreated. Transplantation of unsorted spleen-derived cells from untreated secondary SCID mice injected with spleen cells from AS/IFN $\alpha$-treated primary mice into tertiary SCID mice revealed a delayed and progressive loss of LIC activity starting at week 7 and reaching complete exhaustion by week 9 (Figure 4B). Interestingly, spleen cells derived from untreated secondary mice sacrificed at weeks 4, 5 and 6 maintained their long-term LIC activity in serial transplantation experiments in tertiary and quaternary recipient SCID mice (Figure 4B green histograms, Online Supplementary Figure S4A). Hence, early isolation of spleenderived ATL cells from their environment in untreated secondary SCID mice allowed the cells to maintain their leukemia-initiating activity, which would have been lost if the cells had been kept in their original environment. LIC activity was preserved when unsorted spleen-derived cells from untreated secondary SCID mice were transplanted into tertiary NOG SCID mice (Figure 4C), pointing to a critical role of recipient innate immunity in this delayed eradication of LIC activity. To confirm this finding, we measured levels of pro-inflammatory cytokines in sorted $\mathrm{CD}_{25} 5^{+}$or $\mathrm{CD}^{2} 5^{-}$cells from spleens of untreated secondary SCID mice sacrificed at weeks 4 to 8 (see experimental design in Figure 4D). A gradual and significant increase of the production of IL-12, IFN $\gamma$, MCP-1, MIP-1 $\alpha$, RANTES and IL-15 (Figure 4D, Online Supplementary Figure S4B) was observed exclusively in the CD25 non-leukemic fraction, starting in week 6 or 7 . This delayed production of proinflammatory cytokines by non-malignant cells in the microenvironment is concomitant with the delayed loss of ATL LIC activity.

\section{Loss of interleukin-10 production by Tax-driven leukemic cells is an early event preceding the loss of leukemic-initiating cell activity}

Contrary to pro-inflammatory cytokines, IL-10 was selectively produced by the Tax-driven CD25+ leukemic subpopulation. IL-10 protein and transcript levels significantly and rapidly decreased in untreated secondary recipients injected with spleen cells from AS/IFN $\alpha$-treated primaries (Figure 5A, Online Supplementary Figure 5A). The decrease of IL-10 levels was accompanied by the reduction of its downstream STAT3 signaling (Figure 5B). Similarly, treatment of primary ATL SCID mice with antiIL-10 monoclonal antibody resulted in a decrease of pSTAT3 (Online Supplementary Figure 5B). Collectively, these results demonstrate that treatment of Tax-driven leukemic cells with AS and IFN abrogates their production of IL-10 followed by increased production of proinflammatory cytokines by non-leukemic cells and innate immunity-mediated loss of ATL LIC activity.

\section{Tax knock-down in human adult T-cell leukemia/lymphoma cells decreased interleukin-10 production}

To translate the findings from our murine model to human cells, we treated ATL-derived cell lines HuT-102 or MT-1 with AS/IFN $\alpha$ for $24 \mathrm{~h}$. Tax protein was detectable in HuT-102 cells but not in MT-1 cells or HTLV-1-negative Jurkat cells (Online Supplementary Figure S5C). As previously reported ${ }^{28} \mathrm{AS} / \mathrm{IFN \alpha}$ induced proteasomal-mediated Tax degradation (Online Supplementary Figure S5C). Treatment with AS/IFN $\alpha$ significantly decreased IL-10 expression, exclusively in ATL-derived cell lines (Figure 5C). Importantly, this AS/IFN $\alpha$-induced loss of IL-10 production was rescued upon co-treatment with PS-341 (Figure $5 \mathrm{C})$, suggesting that the effect of AS/IFN $\alpha$ on IL-10 production involves Tax degradation by the proteasome. Importantly, no effect was observed on the HTLV-1-negative Jurkat $\mathrm{T}$ cell line (Figure $5 \mathrm{C}$ ). Similar results were observed upon ex-vivo treatment of PBMC from six patients with ATL ( 3 with acute ATL and 3 with chronic ATL). These PBMC were treated ex-vivo with AS/IFN $\alpha$ for $24 \mathrm{~h}$, before sorting the CD25+ and CD25- subpopulations of cells. Of note, and as previously reported, baseline IL10 transcripts levels were significantly higher in the PBMC of patients with ATL than in those of HTLV-1-negative controls $^{24}$ (Online Supplementary Figure S5D). In patients with ATL, IL-10 was predominantly produced by the CD25 $5^{+}$cells and significantly decreased upon treatment with AS/IFNa (Figure 5D). These results are consistent with the previously reported high IL-10 plasma levels in patients with ATL as compared to levels in healthy donors $^{24}$ and the decrease of IL-10 production following AS/IFNa/AZT therapy. ${ }^{24}$

To directly demonstrate the role of Tax in IL-10 production, we knocked down Tax in HuT-102 or MT-1 cell lines using shRNA. Tax knock-down was verified by real-time PCR (Online Supplementary Figure S5E). Extinction of Tax resulted in a significant decrease of IL-10 protein levels 
(Figure 5E) in the ATL-derived cell line, which expresses high levels of Tax (HuT-102), and in the ATL-derived cell line, which does not express detectable Tax protein (MT1) (Figure 5E, Online Supplementary Figure S5C), but not in HTLV-1-negative Jurkat cells (Figure 5E). Although Tax protein was undetectable in the MT-1 cell line (Online Supplementary Figure S5C), these cells have been shown to sporadically express Tax and such expression is critical for the survival of the whole cell population. ${ }^{11}$ These results highlight the role of Tax in IL-10 production and confirm in human primary ATL cells and ATL-derived cell lines that AS/IFN $\alpha$ treatment decreases IL-10 production.

\section{The triple combination of arsenic, interferon- $\alpha$ and anti-interleukin-10 monoclonal antibodies cures murine adult T-cell leukemia/lymphoma}

The critical role of IL-10 shutdown in suppression of ATL LIC activity incited us to combine IL-10 suppressive therapy with AS and IFN $\alpha$. SCID mice were injected with $10^{6}$ spleen cells and treated as indicated in Figure 6A. Treatment with AS/IFN $\alpha$ or with anti-IL-10 monoclonal antibodies significantly prolonged the survival of primary ATL SCID mice, whereas treatment with the triple combination yielded a 6 -month survival of around $80 \%$ of mice (Figure 6A).

To assess the effects of these combinations on LIC activity, primary ATL SCID mice received short-term treatment (for 3 days) with AS/IFN $\alpha$, anti-IL-10 antibodies, or their triple combination (see experimental design in Figure $6 \mathrm{~B})$. No significant changes in spleen weight, in tax DNA or in the percentage of CD25+ cells were observed following short-term treatment of these primary mice, as compared to the untreated group (Online Supplementary Figure $S 6 A$ ). Importantly, significant increases of the production of the pro-inflammatory cytokines IFN- $\gamma$ and IL-15 as well as MCP-1 and MIP-1 $\alpha$ were observed exclusively in the CD25- spleen cell subpopulation sorted from the treated groups. Furthermore, an additive effect of AS/IFN $\alpha$ and anti-IL-10 antibodies was noted (Online Supplementary Figure S6B). Conversely, IL-10 transcripts (Online Supplementary Figure $S 6 B$ ) and protein (Online Supplementary Figure S6C) were produced by the CD25+ population and were downregulated after treatment with AS/IFN, but only IL-10 protein levels were downregulated by anti-IL-10 antibodies (Online Supplementary Figure S6B and $\mathrm{C}$ ).

As previously reported, ${ }^{21}$ short-term treatment of primary ATL mice with AS/IFN $\alpha$ significantly decreased the ability of Tax-driven leukemic cells to initiate leukemia in untreated secondary recipients. This was demonstrated by the increased survival of untreated secondary SCID mice from a median of 23 days (range, 20-24) to a median of 70 days (range, 67-76) (Figure 6B). Similar results were observed upon short-term treatment of primary mice with anti-IL10 antibodies, which significantly increased survival of untreated secondary mice to a median of 55 days (range, 45-62) (Figure 6B). Strikingly, treatment of primary mice with the triple combination of AS/IFN $\alpha / a n t i-I L 10$ antibodies almost totally abrogated ATL LIC activity in untreated secondary mice (Figure 6B).

Finally, ATL LIC activity was rescued completely when secondary SCID mice, injected with spleen cells derived from primary SCID mice treated with the triple combination of AS/IFNa/anti-IL10 antibodies, were further treated with clodronate or anti-NK1.1 antibodies, confirming the critical role of macrophages and NK cells in the therapeutic efficacy of this triple combination (Figure 6B). These results provide a strong rationale for testing the potential therapeutic effect of the combination of AS/IFN $\alpha$ and anti-IL10 in patients with ATL.

\section{Discussion}

In this study, we unraveled the mechanisms of the curative therapeutic effect of AS/IFN $\alpha$ in murine ATL. We demonstrated that this combination targets both malignant cells and innate immune cells to suppress ATL LIC activity. Indeed, malignant growth was impaired only when malignant cells were exposed to AS/IFN $\alpha$ in the presence of intact innate immunity in both primary donor mice and secondary recipient mice (Figure 6C). Yet, innate immunity alone was not able to prevent growth of untreated malignant cells. At the molecular level, we showed that ATL long-term self-renewal is dependent on IL-10 signaling and AS/IFN $\alpha$ therapy abrogated IL-10 production by the malignant cells. This triggers activation of innate immunity, which subsequently eliminates ATL LIC activity (Figure 6C).

LIC rely on a tight crosstalk between signals from leukemic cells and their neighboring immune microenvironment cells, through their respective cytokine production, for their activity and self-renewal. Indeed, malignant cells release suppressive cytokines and chemokines to evade immune detection and hamper the activity of immune cells. ${ }^{29,30}$ In that sense, patients with ATL exhibit an immunosuppressive cytokine profile characterized by high levels of IL-10 at diagnosis. ${ }^{23,24,29}$ IL-10 can be produced by ATL cells, HTLV-1-infected non-ATL cells or even by HTLV-1-negative cells. ${ }^{23}$ Furthermore, besides its potential immunosuppressive properties, ${ }^{31} \mathrm{IL}-10$ promotes proliferation of HTLV-1-infected cells through the STAT3 and IRF4 pathways. ${ }^{25}$ Interestingly, it was demonstrated that IRF4 and nuclear factor- $\mathrm{B}$ drive ATL maintenance. ${ }^{32}$ Similarly, a recent study showed that the HTLV-1 antisense bZIP factor HBZ upregulates expression of IL-10, interacts with STAT1 and STAT3 and modulates the IL10/JAK/STAT signaling pathway. ${ }^{33}$ In this study, we demonstrate that IL-10 is produced by malignant cells in Tax-driven murine ATL and, importantly, AS/IFN $\alpha$, known to induce Tax degradation, decreased IL-10 levels. Similarly, ex-vivo treatment of ATL-derived cell lines or primary cells from patients with ATL with AS/IFNa decreased IL-10 expression. These results demonstrate a great similarity with the high IL-10 levels in patients with ATL and the decrease of IL-10 following AS/IFNa/AZT therapy. ${ }^{24}$

One prominent observation in our study is the crucial role of innate immunity, particularly NK cells and macrophages, in therapy-induced suppression of ATL LIC and disease cure. This innate immunity is activated by the decrease in IL-10 levels, known to suppress macrophage activity. ${ }^{31}$ Loss of IL-10, following treatment with AS/IFN $\alpha$ or monoclonal antibodies, activates innate immunity. This triggers the production of pro-inflammatory cytokines by NK cells, macrophages, and potentially other components of innate immunity such as dendritic cells and neutrophils, eventually leading to abrogation of ATL LIC activity (Figure 6C). Our results presumably indicate that ATL cells evade the innate immune system through the production 
of IL-10, an anti-inflammatory cytokine that impedes the pro-inflammatory response. Targeted therapies hampering IL-10 production by ATL cells activate an innate immune response which eradicates the disease through abrogation of LIC activity.

Oncogene addiction is a specific feature of LIC, ${ }^{34}$ suggesting that, at least in malignancies with a single rate-limiting genetic event such as some leukemias, oncogene degradation could be used to eradicate LIC and, secondarily, the disease..$^{21,35,36}$ It has been suggested that ATL cells depend on Tax expression for their survival and long-term self-renewal. ${ }^{10,11}$ However, Tax expression is barely detectable in patients with ATL, likely due to the defect of the provirus in ATL cells and 5' long terminal repeat selective heavy CpG methylation in some patients. Yet, transient bursts of Tax expression take place in a small fraction of HTLV-1-infected non-malignant or ATL cells., ${ }^{9,11}$ Nonetheless, this finding still necessitates validation in primary ATL cells. Moreover, in most reported cases, Tax expression was analyzed in cells from peripheral blood but not from lymph nodes, spleen or bone marrow where LIC might be located. In our model, AS/IFN $\alpha$-induced loss of IL-10 production and LIC activity were rescued upon co-treatment with a proteasome inhibitor, suggesting that the curative effect of AS/IFN $\alpha$ in ATL involves Tax degradation by the proteasome..$^{10,21}$ Unfortunately, the undetectable level of Tax protein in tax transgenic murine ATL cells precludes a direct demonstration of therapy-induced Tax degradation in vivo. To overcome this in vivo limitation, we knocked down Tax expression in human ATL-derived cell lines expressing different baseline levels of Tax protein. We demonstrated that extinction of Tax significantly affected IL-10 production, regardless of baseline Tax protein expression, confirming that IL-10 is a downstream target of Tax. Our findings, along with recently reported data on the upregulation of IL-10 expression by the other HTLV-1 regulatory protein $\mathrm{HBZ},{ }^{33}$ highlights the critical role of IL-10 in HTLV-1 infection and the pathogenesis of ATL.

One limitation of our model is that the immune-phenotype of the malignant cells in our model (exclusively CD4CD8- cells) may not reflect that of the majority of ATL cells. In this model, the lack of adaptive immunity allowed us to unravel the critical role of innate immunity in AS/IFN $\alpha$-induced eradication of ATL LIC activity. Nevertheless, therapy-induced loss of IL-10 production likely also activates adaptive immunity in patients with
ATL. Similarly, HTLV-1-infected non-malignant cells normally present in patients with ATL are not encountered in tax transgenic mice. These HTLV-1-infected non-malignant cells can be a source for Tax-dependent IL-10 production in patients with ATL, allowing long-term self-renewal of malignant cells in niches, even in the minority of patients with a defective provirus that lost the ability to express Tax in the malignant cells. Finally, we cannot dismiss the possibility that HTLV-1-negative cells may also participate in the production of IL-10 in patients with ATL and that these may also be targeted by AS/IFN $\alpha$. However, our results in tax transgenic mice are similar to those obtained in ATL-derived cell lines, freshly isolated cells from ATL patients and, importantly, patients with ATL treated with AS/IFNa/AZT. ${ }^{24}$

In conclusion, collectively our results provide a strong rationale for clinical trials combining AS/IFN $\alpha$ with antiIL-10 antibodies in patients with ATL. Furthermore, weekly examination of untreated secondary mice enables a detailed exploration of therapy-induced response to targeted agents in vivo, and disentangles the sequence of events resulting from the effect of treatment on leukemic cells and their environment.

\section{Disclosures}

No conflicts of interest to disclose.

\section{Contributions}

$H E H, R H, J B, M C, A M$ and $A A$ performed experiments; $H E H, M E S, G Z, H H, W H, H d T, O H$ and $A B$ analyzed results; $H E H$ and $R H$ created the figures; $H E H, H d T, O H$ and $A B$ designed the research and wrote the paper.

\section{Acknowledgments}

We thank Drs. Youmna Kfoury and Renaud Mahieux for their critical reading of the manuscript. This manuscript was edited by Life Science Editors.

\section{Funding}

This work was supported by the American University of Beirut Medical Practice Plan, the University Research Board, the Lebanese National Council for Scientific Research, the Lady TATA Memorial Trust; the European Research Council (Senior Grant 268729-STEMAPL) (to HdT), the Ligue Nationale Contre le Cancer, Centre National de la Recherche Scientifique, Association de Recherche Contre le Cancer, Institut National Contre le Cancer, and Cancerople Ile de France (to $\mathrm{OH}$ ).

\section{References}

1. Takatsuki K. [Adult T-cell leukemia]. Nihon Rinsho. 1978;(Suppl):1646-1647

2. Poiesz BJ, Ruscetti FW, Reitz MS, Kalyanaraman VS, Gallo RC. Isolation of a new type $\mathrm{C}$ retrovirus (HTLV) in primary uncultured cells of a patient with Sezary Tcell leukaemia. Nature. 1981;294 (5838):268271.

3. Wattel E, Vartanian JP, Pannetier C, et al. Clonal expansion of human T-cell leukemia virus type I-infected cells in asymptomatic and symptomatic carriers without malignancy. J Virol. 1995;69(5):2863-2868.

4. Kfoury Y, Nasr R, Hermine O, et al. Proapoptotic regimes for HTLV-I-transformed cells: targeting Tax and the NFkappaB pathway. Cell Death Differ. 2005;
12(Suppl 1):871-877.

5. Matsuoka M, Jeang KT. Human T-cell leukemia virus type 1 (HTLV-1) and leukemic transformation: viral infectivity, Tax, HBZ and therapy. Oncogene. 2011; 30(12):1379-1389.

6. Mulloy JC, Kislyakova T, Cereseto A, et al. Human T-cell lymphotropic/leukemia virus type 1 Tax abrogates p53-induced cell cycle arrest and apoptosis through its CREB/ATF functional domain. J Virol. 1998; 72(11):8852-8860.

7. Yoshida M. Multiple viral strategies of HTLV-1 for dysregulation of cell growth control. Annu Rev Immunol. 2001;19:475496.

8. Hasegawa H, Sawa H, Lewis MJ, et al. Thymus-derived leukemia-lymphoma in mice transgenic for the Tax gene of human
T-lymphotropic virus type I. Nat Med. 2006;12(4):466-472

9. Billman MR, Rueda D, Bangham CRM Single-cell heterogeneity and cell-cyclerelated viral gene bursts in the human leukaemia virus HTLV-1. Wellcome Open Res. 2017;2:87.

10. Dassouki Z, Sahin U, El Hajj H, et al. ATL response to arsenic/interferon therapy is triggered by SUMO/PML/RNF4-dependent Tax degradation. Blood. 2015;125(3):474482.

11. Mahgoub M, Yasunaga JI, Iwami S, et al. Sporadic on/off switching of HTLV-1 Tax expression is crucial to maintain the whole population of virus-induced leukemic cells. Proc Natl Acad Sci U S A. 2018; 115(6): E1269-E1278.

12. Suehiro $Y$, Hasegawa $A$, Iino $T$, et al 
Clinical outcomes of a novel therapeutic vaccine with Tax peptide-pulsed dendritic cells for adult $\mathrm{T}$ cell leukaemia/lymphoma in a pilot study. Br J Haematol. 2015; 169(3):356-367.

13. Bazarbachi A, Plumelle Y, Carlos Ramos J, et al. Meta-analysis on the use of zidovudine and interferon-alfa in adult T-cell leukemia/lymphoma showing improved survival in the leukemic subtypes. J Clin Oncol. 2010;28(27):4177-4183.

14. Bazarbachi A, Suarez F, Fields P, et al. How I treat adult T-cell leukemia/lymphoma. Blood. 2011;118(7):1736-1745.

15. Gill PS, Harrington W, Kaplan MH, et al. Treatment of adult T-cell leukemia-lymphoma with a combination of interferon alfa and zidovudine. N Engl J Med. 1995;332(26):1744-1748.

16. Hermine O, Bouscary D, Gessain A, et al. Brief report: treatment of adult T-cell leukemia-lymphoma with zidovudine and interferon alfa. N Engl J Med. 1995; 332(26):1749-1751.

17. Malpica L, Pimentel A, Reis IM, et al. Epidemiology, clinical features, and outcome of HTLV-1-related ATLL in an area of prevalence in the United States. Blood Adv. 2018;2(6):607-620.

18. Bazarbachi A, El-Sabban ME, Nasr R, et al. Arsenic trioxide and interferon-alpha synergize to induce cell cycle arrest and apoptosis in human T-cell lymphotropic virus type I-transformed cells. Blood. 1999; 93(1):278-283.

19. Mahieux R, Pise-Masison C, Gessain A, et al. Arsenic trioxide induces apoptosis in human T-cell leukemia virus type 1 - and type 2-infected cells by a caspase-3-dependent mechanism involving $\mathrm{Bcl}-2$ cleavage. Blood. 2001;98(13):3762-3769.
20. Kchour G, Tarhini M, Kooshyar MM, et al. Phase 2 study of the efficacy and safety of the combination of arsenic trioxide, interferon alpha, and zidovudine in newly diagnosed chronic adult T-cell leukemia/lymphoma (ATL). Blood. 2009;113(26):65286532.

21. El Hajj H, El-Sabban M, Hasegawa H, et al. Therapy-induced selective loss of leukemia-initiating activity in murine adult T cell leukemia. J Exp Med. 2010;207(13): 2785-2792.

22. Marcais A, Cook L, Witkover A, et al. Arsenic trioxide (As2O3) as a maintenance therapy for adult $\mathrm{T}$ cell leukemia/lymphoma. Retrovirology. 2020;17(1):5.

23. Kagdi H, Demontis MA, Ramos JC, et al. Switching and loss of cellular cytokine producing capacity characterize in vivo viral infection and malignant transformation in human T- lymphotropic virus type 1 infection. PLoS Pathog. 2018;14(2):e1006861.

24. Kchour G, Rezaee R, Farid R, et al. The combination of arsenic, interferon-alpha, and zidovudine restores an "immunocompetent-like" cytokine expression profile in patients with adult T-cell leukemia lymphoma. Retrovirology. 2013;10:91.

25. Sawada L, Nagano Y, Hasegawa A, et al. IL10-mediated signals act as a switch for lymphoproliferation in human T-cell leukemia virus type- 1 infection by activating the STAT3 and IRF4 pathways. PLoS Pathog. 2017;13(9):e1006597.

26. Ito $M$, Hiramatsu $H$, Kobayashi $K$, et al. NOD/SCID/gamma(c)(null) mouse: an excellent recipient mouse model for engraftment of human cells. Blood. 2002; 100(9):3175-3182.

27. Weisser SB, van Rooijen N, Sly LM Depletion and reconstitution of macrophages in mice. J Vis Exp. 2012; (66):4105.

28. El-Sabban ME, Nasr R, Dbaibo G, et al Arsenic-interferon-alpha-triggered apoptosis in HTLV-I transformed cells is associated with tax down-regulation and reversal of NF- $\mathrm{kB}$ B activation. Blood. 2000; 96(8): 2849-2855.

29. Camacho V, McClearn V, Patel S, et al Regulation of normal and leukemic stem cells through cytokine signaling and the microenvironment. Int J Hematol. 2017; 105(5):566-577.

30. Gun SY, Lee SWL, Sieow JL, et al. Targeting immune cells for cancer therapy. Redox Biol. 2019;25:101174.

31. Couper KN, Blount DG, Riley EM. IL-10 the master regulator of immunity to infection. J Immunol. 2008;180(9):5771-5777.

32. Wong RWJ, Tan TK, Amanda S, et al. Feedforward regulatory loop driven by IRF4 and NF- $\mathrm{KB}$ in adult T-cell leukemia/lymphoma. Blood. 2020;135(12):934-947.

33. Higuchi Y, Yasunaga JI, Mitagami Y, et al. HTLV-1 induces T cell malignancy and inflammation by viral antisense factormediated modulation of the cytokine signaling. Proc Natl Acad Sci U S A. 2020; 117(24):13740-13749.

34. Weinstein IB. Cancer. Addiction to oncogenes: the Achilles heal of cancer. Science. 2002;297(5578):63-64.

35. Ablain J, Rice K, Soilihi H, et al. Activation of a promyelocytic leukemia-tumor protein 53 axis underlies acute promyelocytic leukemia cure. Nat Med. 2014;20(2):167174.

36. Nasr R, Guillemin MC, Ferhi O, et al Eradication of acute promyelocytic leukemia-initiating cells through PMLRARA degradation. Nat Med. 2008; 14(12):1333-1342. 